\title{
Association Between Serum Uric Acid Levels and Atrial Fibrillation Risk
}

\author{
Chun-Hong Zhang Dang-Sheng Huang Dong Shen Li-Wei Zhang \\ Yong-Jiang Ma Yu-Mei Wang Hong-Yan Sun \\ Cardiovascular Department, First Affiliated Hospital to PLA General Hospital, Beijing, P.R.China
}

\author{
Key Words \\ Hyperuricemia • Atrial fibrillation • Meta-analysis
}

\begin{abstract}
Background: Several studies were published to assess the association between serum uric acid levels and atrial fibrillation risk, but no consistent results were reported. We performed a meta-analysis to evaluate the evidence of the association between hyperuricemia and atrial fibrillation risk. Material/Methods: Pubmed and Embase databases were searched for prospective cohort studies assessing the association between hyperuricemia and atrial fibrillation risk. Relative risks (RRs) with corresponding 95\% confidence intervals (95\%CIs) were pooled using random-effect of meta-analysis to assess the risk of atrial fibrillation in individuals with hyperuricemia. Results: Six cohort studies were finally included into the meta-analysis. Meta-analysis of those 6 studies showed that hyperuricemia was significantly associated with increased risk of atrial fibrillation ( $R R=1.49,95 \% C I 1.24-1.79, \mathrm{P}<0.001)$. Sensitivity analysis by omitting single study sequentially by turns did not have any obvious influence on the pooled risk estimates. There was no obvious risk of publication bias in the meta-analysis. Conclusions: Based on the currently available data, hyperuricemia is associated with increased risk of atrial fibrillation.

\section{Introduction}

Atrial fibrillation is a common disease in the elderly, and it's also associated with increased risk of cardiovascular disease and stroke [1-3]. There are increased incidence and prevalence of atrial fibrillation in the world [4]. The management of atrial fibrillation has evolved greatly in the past few years, and there are many substantial advances or developments in the treatment of atrial fibrillation [5]. Multiple pieces of evidence indicate that the development of atrial fibrillation depends on the electrophysiological and structural remodeling of the atria. However, the exact pathogenesis of atrial fibrillation is still not well understood, and a better understanding of its exact pathogenesis can help us to develop new 


\section{Cellular Physiology Cell Physiol Biochem 2016;38:1589-1595 \begin{tabular}{l|l} 
DOI: 10.1159/000443099 & $\begin{array}{l}\text { O 2016 S. Karger AG, Basel } \\
\text { www.karger.com/cpb }\end{array}$ \\
\hline
\end{tabular} \\ Zhang et al.: Uric Acid and Atrial Fibrillation}

treatments or preventive methods [4, 6, 7]. Several risk factors have been identified for atrial fibrillation, such as obesity, and diabetes [8-12]. Inflammation has been demonstrated in the pathophysiological mechanism of atrial fibrillation [5, 12-14]. The uric acid is the endproduct during the purine degradation in humans, and it has emerged as risk factors of many common diseases including cardiovascular diseases. In addition, uric acid has been clearly associated with inflammation and oxidative stress, and it can promote inflammation via the activation of pro-inflammatory cytokines $[15,16]$. Several studies were published to assess the association between serum uric acid levels and atrial fibrillation risk, but no consistent results were reported [17-24]. We thus performed a meta-analysis to evaluate the evidence of the association between serum uric acid levels and atrial fibrillation risk.

\section{Materials and Methods}

\section{Search strategy and study selection}

Pubmed and Embase databases were searched for prospective cohort studies that were published to assess the association between hyperuricemia and atrial fibrillation risk. The last search was performed on October 16, 2015. The search strategy used in the meta-analysis was as following: (atrial fibrillation) and (urate OR uric acid OR hyperuricemia). Hand searching of selected journals and cross checking of bibliographies from other published reviews or relevant articles was also done to supplement the electronic searches. After removal of duplicate references, initial screening of article titles and abstracts was performed by two members of the review team. Full texts of potentially relevant articles were obtained and assessed independently by two members of the review team using a structured flow chart and detailed guidelines. Any disagreements were settled by discussion among all members of the review team.

The inclusion criteria were as following: (1) Prospective cohort studies; (2) Assessing the effect of hyperuricemia on risk of atrial fibrillation; (3) Reported risk estimates for atrial fibrillation, such as relative risks (RR), hazard ratios (HR), or odds ratios (OR) with 95\% confidence intervals (95\%CI). When more than 2 publications reported outcomes from the same study, only the one with the longest follow-up or largest dataset was included into the meta-analysis.

\section{Data extraction and quality assessment}

The following data were extracted from each study: first author, study design, country, baseline characteristics, follow-up, number of participants, number of cases, adjusted factors, and RRs and their 95\%CIs. The quality of included studies was assessed using the Newcastle Ottawa scale (NOS) as recommended by the Cochrane Non-Randomized Studies Methods Working Group [25]. Quality was assigned as A or excellent with 7-9 stars, B or good with 4-6 stars, and C or suboptimal with 0-3 stars. Only studies with excellent or good quality were finally included into the analysis.

\section{Statistical analysis}

To evaluate the association between serum uric acid levels and atrial fibrillation risk, we used metaanalysis to calculate the pooled RR and 95\%CI under a random-effect model [26]. The I statistic method was used to evaluate the between-study heterogeneity [27]. The significance of pooled RR was determined by the $\mathrm{Z}$ test, and a P value of less than 0.05 was considered significant. Sensitivity analysis was performed by sequentially omitted single study by turns. To assess the risk of publication bias, our meta-analysis used both funnel plot and Egger's test [28]. Statistical analyses were performed using STATA 12.0 (StataCorp, College Station, Texas, USA). P value less than 0.05 was considered significant.

\section{Results}

\section{Study characteristics}

Through the literature search of Pubmed and Embase databases, 126 individual abstracts were found, 115 abstracts were firstly excluded after reviewing the abstracts. 11 full-text articles were reviewed for more detailed evaluation. After full-text evaluation, 5 
Table 1. Baseline characteristics of those studies included into the meta-analysis

\begin{tabular}{|c|c|c|c|c|c|}
\hline Study, Year & Design & Number of participants & Country & $\begin{array}{c}\text { Follow- } \\
\text { up }\end{array}$ & $\begin{array}{l}\text { Quality } \\
\text { Score }\end{array}$ \\
\hline Kim (2015)[33] [42] & $\begin{array}{l}\text { Prospective } \\
\text { cohort }\end{array}$ & $\begin{array}{l}70015 \text { gout patients and } 210045 \\
\text { controls }\end{array}$ & USA & 2 years & 8 \\
\hline Chuang (2014)[29] & $\begin{array}{c}\text { Prospective } \\
\text { cohort }\end{array}$ & 1485 elderly persons & Taiwan & 9.2 years & 8 \\
\hline Nyrnes (2014)[21] & $\begin{array}{c}\text { Prospective } \\
\text { cohort }\end{array}$ & 6308 persons & Norway & $\begin{array}{c}10.8 \\
\text { years }\end{array}$ & 8 \\
\hline Chao (2013)[31] & $\begin{array}{c}\text { Prospective } \\
\text { cohort }\end{array}$ & 122,524 persons & Taiwan & 6.3 years & 9 \\
\hline Valbusa (2013)[30] & $\begin{array}{c}\text { Prospective } \\
\text { cohort }\end{array}$ & 400 persons & Italy & 10 years & 6 \\
\hline Tamariz (2011)[32] & $\begin{array}{c}\text { Prospective } \\
\text { cohort }\end{array}$ & 15,382 persons & $\begin{array}{l}\text { United } \\
\text { States }\end{array}$ & $\begin{array}{c}16.8 \\
\text { years }\end{array}$ & 9 \\
\hline
\end{tabular}

\begin{tabular}{|c|c|c|c|}
\hline Study & & & $\%$ \\
\hline ID & & $\mathrm{RR}(95 \% \mathrm{Cl})$ & Weight \\
\hline Kim (2015) & $\rightarrow$ & $1.21(1.11,1.33)$ & 28.88 \\
\hline Chuang(2014) & & $2.65(1.05,6.69)$ & 3.51 \\
\hline Nyrnes(2014) & & $1.98(1.34,2.92)$ & 13.01 \\
\hline Chao(2013) & $\leftarrow$ & $1.19(1.09,1.29)$ & 29.15 \\
\hline Valbusa(2013) & & $3.51(1.50,8.20)$ & 4.09 \\
\hline Tamariz(2011) & & $1.74(1.39,2.17)$ & 21.36 \\
\hline Overall (I-squared $=79.0 \%, p=0.000)$ & & $1.49(1.24,1.79)$ & 100.00 \\
\hline NOTE: Weights are from random effects analysis & & & \\
\hline .122 & 1 & 8.2 & \\
\hline
\end{tabular}

Fig. 1. Hyperuricemia was significantly associated with atrial fibrillation risk.

articles were further excluded, and 6 cohort studies finally met the inclusion criteria and were included [21, 29-33]. Table 1 showed the main baseline characteristics of those 5 cohort studies included into the meta-analysis (Table 1).Those 6 studies involved a total of 426,159 participants (Table 1). The sample size ranged from 400 to 280,060 persons (Table 1 ), while the time of follow-up ranged from 2 years to 16.8 years (Table 1 ). As to the quality assessment by NOS Scale, the scores ranged from 6 to 9 points, and all studies had excellent or good quality (Table 1 ).

\section{Meta-analysis}

Meta-analysis of those 6 studies showed that hyperuricemia is significantly associated with increased risk of atrial fibrillation $(\mathrm{RR}=1.49,95 \% \mathrm{CI} 1.24-1.79, \mathrm{P}<0.001)$ (Fig. 1). 


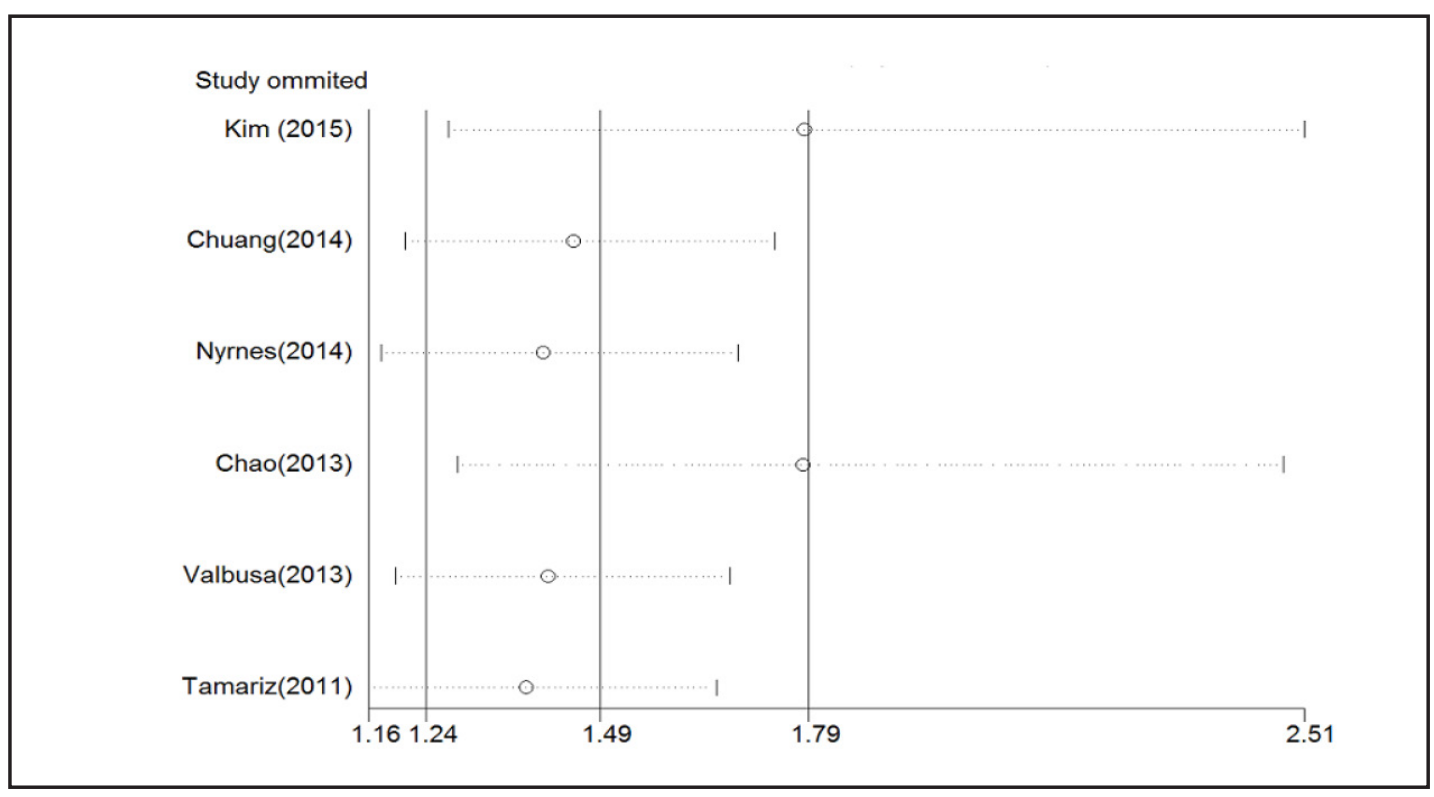

Fig. 2. Forest plot showed the results of sensitivity analysis.

Sensitivity analysis by omitting single study sequentially by turns did not show any obvious influence on the pooled estimates, which further confirmed the findings in the direction and magnitude of the present meta-analysis (Fig. 2).

Funnel plot's shape revealed some evidence of asymmetry in the meta-analysis. In addition, and the P value of Egger's test was more than 0.022 which was less than 0.05 . Thus, there was possible risk of publication bias in the meta-analysis.

\section{Discussion}

We performed a meta-analysis to evaluate the evidence of the association between hyperuricemia and atrial fibrillation risk. Six cohort studies were finally included into the meta-analysis. Meta-analysis of total 6 studies showed that hyperuricemia was significantly associated with increased risk of atrial fibrillation $(\mathrm{RR}=1.49,95 \% \mathrm{CI} 1.24-1.79, \mathrm{P}<0.001)$. Sensitivity analysis by omitting single study sequentially by turns did not show any obvious influence on the pooled estimates (Fig. 2). Thus, our meta-analysis suggests that hyperuricemia is obviously associated with increased risk of atrial fibrillation.

Hyperuricemia has been shown to be associated with risk of several cardiovascular diseases, such as coronary heart disease and stroke [34, 35]. In present study, we found that hyperuricemia is obviously associated with increased risk of atrial fibrillation. Since atrial fibrillation is a common and important risk factor of coronary heart disease and stroke, the finding in the meta-analysis may explain the associations of hyperuricemia with coronary heart disease and stroke, namely atrial fibrillation caused by hyperuricemia further results in coronary heart disease and stroke $[10,36]$.

Serum uric acid is the end product of purine degradation in humans. Uric acid can promotes inflammation via the activation of pro-inflammatory cytokines [37]. At present, serum uric acid has emerged as risk factors of cardiovascular diseases. In addition, uric acid has been clearly associated with inflammation and oxidative stress in several pathological conditions, and it can promote inflammation via the activation of pro-inflammatory cytokines, such as interleukin-1 $\beta$ and tumor necrosis factor- $\alpha$ (TNF- $\alpha)[15,16,38,39]$. Inflammation and oxidative stress has been demonstrated in the pathophysiological mechanism of atrial fibrillation [5, 12-14], and thus uric acid may be also have certain roles in the development of atrial fibrillation. A recent research showed that intracellular urate taken up by uric acid 
transporters could enhance the Kv1.5 protein expression and function in atrial myocytes, which may result from oxidative stress derived from nicotinamide adenine dinucleotide phosphate (NADPH)-oxidase [40]. However, more studies are needed to investigate the exact mechanism underling the roles of uric acid in atrial fibrillation.

The findings from previous studies and present meta-analysis have provided strong evidence for hyperuricemia as important risks of several common cardiovascular diseases. Thus, risk of cardiovascular diseases in hyperuricemia individuals may be effectively decreased through allopurinol treatment. A recent meta-analysis suggest that treatment of hyperuricemia with allopurinol is associated with an improvement in endothelial function [41]. However, results from other literatures are still unable to provide a definite conclusion on the preventive effect of allopurinol against cardiovascular diseases [42, 43]. Further studies are needed to further assess the effect of uric acid lowering therapy on atrial fibrillation risk or cardiac events and death in individuals with atrial fibrillation.

Though there was a conclusive and reliable finding in the meta-analysis, there were several limitations needing to be acknowledged. The limited number of included studies decreased the credibility of the pooled results in the meta-analysis. There were only five cohort studies in our study. More studies are needed to further validate the findings in our meta-analysis. In addition, most of those studies were from limited areas of the world, the findings in the meta-analysis might not be generalized to all populations. Studies from different countries are necessity to add further evidence. Finally, most included did not consider uric acid lowering therapy when performing multivariable logistic regression analyses. To get a more precise evaluation of hyperuricemia on atrial fibrillation, future studies of large cohorts and prospective analyses are required to confirm the role of uric acid as a risk determinant for atrial fibrillation.

In summary, our meta-analysis suggests that hyperuricemia is obviously associated with increased risk of atrial fibrillation. Further studies are needed to further assess the effect of uric acid lowering therapy on atrial fibrillation risk or cardiac events and death in individuals with atrial fibrillation.

\section{Disclosure Statement}

No conflicts of interest to be noted.

\section{References}

1 O'Donnell MJ, Xavier D, Liu L, Zhang H, Chin SL, Rao-Melacini P, Rangarajan S, Islam S, Pais P, McQueen MJ, Mondo C, Damasceno A, Lopez-Jaramillo P, Hankey GJ, Dans AL, Yusoff K, Truelsen T, Diener HC, Sacco RL, Ryglewicz D, Czlonkowska A, Weimar C, Wang X, Yusuf S: Risk factors for ischaemic and intracerebral haemorrhagic stroke in 22 countries (the interstroke study): A case-control study. Lancet 2010;376:112123.

2 Jacobs V, Cutler MJ, Day JD, Bunch TJ: Atrial fibrillation and dementia. Trends Cardiovasc Med 2015;25:4451.

3 Verheugt FW, Granger CB: Oral anticoagulants for stroke prevention in atrial fibrillation: Current status, special situations, and unmet needs. Lancet 2015;386:303-310.

4 Schnabel RB, Yin X, Gona P, Larson MG, Beiser AS, McManus DD, Newton-Cheh C, Lubitz SA, Magnani JW, Ellinor PT, Seshadri S, Wolf PA, Vasan RS, Benjamin EJ, Levy D: 50 year trends in atrial fibrillation prevalence, incidence, risk factors, and mortality in the framingham heart study: A cohort study. Lancet 2015;386:154-162.

$5 \quad$ Lip GY, Tse HF, Lane DA: Atrial fibrillation. Lancet 2012;379:648-661. 


\section{Cellular Physiology Cell Physiol Biochem 2016;38:1589-1595

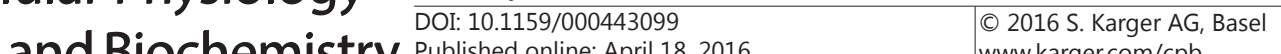 and Biochemistry Published online: April 18, 2016

6 Reilly S, Liu X, Carnicer R, Rajakumar T, Sayeed R, Krasopoulos G, Verheule S, Fulga T, Schotten U, Casadei B: Evaluation of the role of mir-31-dependent reduction in dystrophin and nnos on atrial-fibrillation-induced electrical remodelling in man. Lancet 2015;385:S82.

7 Liu Y, Geng J, Li Y, Shen J, Xiao X, Sheng L, Yang B, Cheng C, Li W: Beta3-adrenoceptor mediates metabolic protein remodeling in a rabbit model of tachypacing-induced atrial fibrillation. Cell Physiol Biochem 2013;32:1631-1642.

8 Huxley RR, Misialek JR, Agarwal SK, Loehr LR, Soliman EZ, Chen LY, Alonso A: Physical activity, obesity, weight change, and risk of atrial fibrillation: The atherosclerosis risk in communities study. Circ Arrhythm Electrophysiol 2014;7:620-625.

9 Rodriguez CJ, Soliman EZ, Alonso A, Swett K, Okin PM, Goff DC Jr, Heckbert SR: Atrial fibrillation incidence and risk factors in relation to race-ethnicity and the population attributable fraction of atrial fibrillation risk factors: The multi-ethnic study of atherosclerosis. Ann Epidemiol 2015;25:71-76, 76 e71.

10 Global Burden of Metabolic Risk Factors for Chronic Diseases Collaboration: Cardiovascular disease, chronic kidney disease, and diabetes mortality burden of cardiometabolic risk factors from 1980 to 2010 : A comparative risk assessment. Lancet Diabetes Endocrinol 2014;2:634-647.

11 Charakida M, Khan T, Johnson W, Finer N, Woodside J, Whincup PH, Sattar N, Kuh D, Hardy R, Deanfield J: Lifelong patterns of bmi and cardiovascular phenotype in individuals aged 60-64 years in the 1946 british birth cohort study: An epidemiological study. Lancet Diabetes Endocrinol 2014;2:648-654.

12 Cox AJ, West NP, Cripps AW: Obesity, inflammation, and the gut microbiota. Lancet Diabetes Endocrinol 2015;3:207-215.

13 Korantzopoulos P, Letsas KP, Liu T: Xanthine oxidase and uric acid in atrial fibrillation. Front Physiol 2012;3:150.

14 Letsas KP, Korantzopoulos P, Filippatos GS, Mihas CC, Markou V, Gavrielatos G, Efremidis M, Sideris A, Kardaras F: Uric acid elevation in atrial fibrillation. Hellenic J Cardiol 2010;51:209-213.

15 So A, Thorens B: Uric acid transport and disease. J Clin Invest 2010;120:1791-1799.

16 Rock KL, Kataoka H, Lai JJ: Uric acid as a danger signal in gout and its comorbidities. Nat Rev Rheumatol 2013;9:13-23.

17 He XN, Li SN, Zhan JL, Xie SL, Zhang ZJ, Dong JZ, Yu RH, Long DY, Tang RB, Ma CS: Serum uric acid levels correlate with recurrence of paroxysmal atrial fibrillation after catheter ablation. Chin Med J (Engl) 2013;126:860-864.

18 Tekin G, Tekin YK, Erbay AR, Turhan H, Yetkin E: Serum uric acid levels are associated with atrial fibrillation in patients with ischemic heart failure. Angiology 2013;64:300-303.

19 Canpolat U, Aytemir K, Yorgun H, Sahiner L, Kaya EB, Cay S, Topaloglu S, Aras D, Oto A: Usefulness of serum uric acid level to predict atrial fibrillation recurrence after cryoballoon-based catheter ablation. Europace 2014;16:1731-1737.

20 Chao TF, Liu CJ, Chen SJ, Wang KL, Lin YJ, Chang SL, Lo LW, Hu YF, Tuan TC, Chen TJ, Tsao HM, Chen SA: Hyperuricemia and the risk of ischemic stroke in patients with atrial fibrillation--could it refine clinical risk stratification in af? Int J Cardiol 2014;170:344-349.

21 Nyrnes A, Toft I, Njolstad I, Mathiesen EB, Wilsgaard T, Hansen JB, Lochen ML: Uric acid is associated with future atrial fibrillation: An 11-year follow-up of 6308 men and women--the tromso study. Europace 2014;16:320-326.

22 Sanchis-Gomar F, Perez-Quilis C, Cervellin G, Lucia A, Lippi G: Anti-gout drugs as potential therapy for atrial fibrillation. Int J Cardiol 2014;177:1061-1062.

23 Tang RB, Dong JZ, Yan XL, Du X, Kang JP, Wu JH, Yu RH, Long DY, Ning M, Sang CH, Jiang CX, Salim M, Bai R, Yao Y, Ma CS: Serum uric acid and risk of left atrial thrombus in patients with nonvalvular atrial fibrillation. Can J Cardiol 2014;30:1415-1421.

24 Wan YF, Zheng YL, Niu HY, Xu CQ, He YQ, Wang Y, Chen JH, Zheng DH: Uric acid levels in obstructive sleep apnea patients with atrial fibrillation. Arch Med Res 2014;45:132-137.

25 Stang A: Critical evaluation of the newcastle-ottawa scale for the assessment of the quality of nonrandomized studies in meta-analyses. Eur J Epidemiol 2010;25:603-605.

26 DerSimonian R, Laird N: Meta-analysis in clinical trials. Control Clin Trials 1986;7:177-188.

27 Higgins JP, Thompson SG, Deeks JJ, Altman DG: Measuring inconsistency in meta-analyses. BMJ 2003;327:557-560. 


\section{Cellular Physiology Cell Physiol Biochem 2016;38:1589-1595 \begin{tabular}{c|c|c|}
\hline DOI: 10.1159/000443099 & O 2016 S. Karger AG, Basel \\
\hline
\end{tabular} www.karger.com/cpb \\ Zhang et al.: Uric Acid and Atrial Fibrillation}

28 Egger M, Davey Smith G, Schneider M, Minder C: Bias in meta-analysis detected by a simple, graphical test. BMJ 1997;315:629-634.

29 Chuang SY, Wu CC, Hsu PF, Chia-Yu Chen R, Liu WL, Hsu YY, Pan WH: Hyperuricemia and incident atrial fibrillation in a normotensive elderly population in taiwan. Nutr Metab Cardiovasc Dis 2014;24:1020-1026.

30 Valbusa F, Bertolini L, Bonapace S, Zenari L, Zoppini G, Arcaro G, Byrne CD, Targher G: Relation of elevated serum uric acid levels to incidence of atrial fibrillation in patients with type 2 diabetes mellitus. Am J Cardiol 2013;112:499-504.

31 Chao TF, Hung CL, Chen SJ, Wang KL, Chen TJ, Lin YJ, Chang SL, Lo LW, Hu YF, Tuan TC, Chen SA: The association between hyperuricemia, left atrial size and new-onset atrial fibrillation. Int J Cardiol 2013;168:4027-4032.

32 Tamariz L, Agarwal S, Soliman EZ, Chamberlain AM, Prineas R, Folsom AR, Ambrose M, Alonso A: Association of serum uric acid with incident atrial fibrillation (from the atherosclerosis risk in communities [aric] study). Am J Cardiol 2011;108:1272-1276.

33 Kim SC, Liu J, Solomon DH: Risk of incident atrial fibrillation in gout: A cohort study. Ann Rheum Dis 2015; doi: 10.1136/annrheumdis-2015-208161.

34 Kim SY, Guevara JP, Kim KM, Choi HK, Heitjan DF, Albert DA: Hyperuricemia and coronary heart disease: A systematic review and meta-analysis. Arthritis Care Res (Hoboken) 2010;62:170-180.

35 Abeles AM: Hyperuricemia, gout, and cardiovascular disease: An update. Curr Rheumatol Rep 2015;17:495.

36 Faerch K, Witte DR, Tabak AG, Perreault L, Herder C, Brunner EJ, Kivimaki M, Vistisen D: Trajectories of cardiometabolic risk factors before diagnosis of three subtypes of type 2 diabetes: A post-hoc analysis of the longitudinal whitehall ii cohort study. Lancet Diabetes Endocrinol 2013;1:43-51.

37 Wu AH, Gladden JD, Ahmed M, Ahmed A, Filippatos G: Relation of serum uric acid to cardiovascular disease. Int J Cardiol 2015

38 Hong Q Yu S, Mei Y, Lv Y, Chen D, Wang Y, Geng W, Wu D, Cai G, Chen X: Smilacis glabrae rhizoma reduces oxidative stress caused by hyperuricemia via upregulation of catalase. Cell Physiol Biochem 2014;34:16751685.

39 Zhang Y, Hong Q, Huang Z, Xue P, Lv Y, Fu B, Chen X, Wu D: Aldr enhanced endothelial injury in hyperuricemia screened using silac. Cell Physiol Biochem 2014;33:479-490.

40 Maharani N, Ting YK, Cheng J, Hasegawa A, Kurata Y, Li P, Nakayama Y, Ninomiya H, Ikeda N, Morikawa K, Yamamoto K, Makita N, Yamashita T, Shirayoshi Y, Hisatome I: Molecular mechanisms underlying urateinduced enhancement of kv1.5 channel expression in hl-1 atrial myocytes. Circ J 2015;79:2659-2668.

41 Kanbay M, Siriopol D, Nistor I, Elcioglu OC, Telci O, Takir M, Johnson RJ, Covic A: Effects of allopurinol on endothelial dysfunction: A meta-analysis. Am J Nephrol 2014;39:348-356.

42 Kim SC, Schneeweiss S, Choudhry N, Liu J, Glynn RJ, Solomon DH: Effects of xanthine oxidase inhibitors on cardiovascular disease in patients with gout: A cohort study. Am J Med 2015, doi: 10.1016/j. amjmed.2015.01.013.

43 Guedes M, Esperanca A, Pereira AC, Rego C: What is the effect on cardiovascular events of reducing hyperuricemia with allopurinol? An evidence-based review. Rev Port Cardiol 2014;33:727-732. 